\title{
AUTISMO E
PARENTALIDADE \\ AUTISMO E
PARENTALIDADE
}

As patologias autísticas são complexas e requerem uma atenção especifica para cada criança. $\mathrm{Na}$ organização que preside os tratamentos, a Psicoterapia Institucional tem uma grande importância devido à sua larga experiência com as psicopatologias graves como o autismo e a psicose. No projeto terapêutico da criança, a implicação e o papel dos pais são determinantes para sua orientação e indispensáveis para dar-

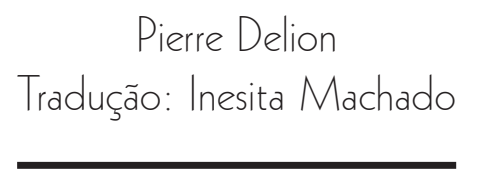

Pierre Delion lhe sentido. Contudo, por razões distintas, alguns pais podem desenvolver sentimentos negativos frente aos profissionais, que devem ser considerados.

Descritores: autismo infantil; pais; psicoterapia institucional; constelação transferencial; tratamentos pedopsiquiátricos.

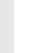

(n)
\section{.}


como deficientes mentais, ou para hospitais psiquiátricos no caso de graves transtornos do comportamento.

Seria preciso ver com os próprios olhos os serviços infantis dos hospitais psiquiátricos que ainda existiam nos anos 1970 para compreender de que região desumana eles se originaram. O estabelecimento da setorização na França e os conceitos da Psicoterapia Institucional possibilitaram uma mudança profunda dessa paisagem, criando hospitais-dia que trabalham em colaboração com os pais das crianças em questão.

Tosquelles (2006) na Lozère, Misès (1980) em Paris, Hochmann (1976) em Lyon, e outros contribuíram para o desenvolvimento de lugares de tratamento humanizados, acolhendo as crianças autistas e psicóticas durante o dia, com experiências de integração escolar em meio período, recebendo os pais regularmente para discutir com eles sobre as dificuldades encontradas e sobre os progressos realizados. Esses exemplos históricos proporcionaram às equipes do setor de Psiquiatria Infantil a possibilidade de tornar modelo suas práticas e reflexões, o que conduziu numerosas e fecundas experiências em todo o território nacional (Delion, 2011).

Os psiquiatras infantis se mobilizaram para auxiliar na inclusão escolar e para desenvolver possibilidades de participação em atividades da cidade. Desse modo, muitas equipes criaram oficinas temáticas, cultivando as diversas artes (música, pintura, dança, fotografia etc.), esportes (natação, vela, escalada, equitação etc.), viagens terapêuticas (para ver o mar, a neve, campo, montanha etc.), para facilitar o acesso à intersubjetividade com base em diferentes formas que a relação pode assumir em nossa humanidade contemporânea.

As equipes também desenvolveram técnicas corporais e psíquicas (psicomotricidade), de palavra (fonoaudiologia) e psicoterápicas que enriqueciam as possibilidades relacionais dessas crianças enigmáticas. No entanto, todos os profissionais em questão se comprometiam em participar de um verdadeiro trabalho de equipe com a criança e seus pais. De fato, a própria qualidade do laço da criança com o mundo requer uma abordagem grupal para não dispersar os laços frágeis que ela instaura com seu meio ambiente.

O conceito de "constelação transferencial" se aplica particularmente ao trabalho com essas crianças. Trata-se de reunir regularmente os profissionais em contato com elas e poder fazer trocas dos elementos recolhidos por cada um para o estabelecimento de uma representação complexa desses laços com o mundo humano. Um dos efeitos maiores da constelação transferencial é o de proporcionar à criança uma função 
continente que lhe permita lutar de modo eficaz contra suas angústias arcaicas.

Esse dispositivo vem dos trabalhos da Psicoterapia Institucional, movimento que refletiu intensamente sobre a qualidade da relação de transferência em patologias graves como a psicose e o autismo. Com efeito, não se trata de "receber" uma criança autista em um "tratamento padrão" dentro do modelo proposto por Freud em sua psicanálise das neuroses clássicas. Em contrapartida, é interessante constatar que a relação de transferência de uma criança autista é fundada sobre o modo dos objetos parciais, e que cada encontro será para ela a ocasião de desenvolver uma relação singular com um cuidador no modo prevalente da identificação adesiva patológica (Delion, 2009).

Essas relações podem ser extremamente diversas e só a reunião da constelação transferencial pode dar uma representação da complexidade da relação da criança autista com o mundo. Mas o que parece simples de representar nesse dispositivo é na verdade muito complexo. Efetivamente, não basta decretar uma reunião da constelação para que ela ocorra sem dificuldades. É preciso poder falar de modo autêntico nesses lugares para que haja uma maior proximidade da qualidade das relações consideradas.

O sistema hierárquico clássico dos hospitais é pouco propício a tal clima de facilitação da palavra; é preciso poder desenvolver um sistema hierárquico com base nas competências de cada um e não apenas sobre os estatutos. De fato, um pequeno autista pouco se importa com os estatutos profissionais, e pode ocorrer que ele seja muito apegado à pessoa que prepara bolos, enquanto se recusa a ir ao fonoaudiólogo ou ao psicoterapeuta. A constelação transferencial permite considerar a relação dessa criança com a cozinheira e pensar uma estratégia terapêutica que a leve em conta. Não se trata de dizer que a cozinheira poderá se instalar como psicoterapeuta, mas de considerar que ela participe da função psicoterápica dentro do coletivo de tratamento (Oury, 1986).

O movimento de Psicoterapia Institucional transformou profundamente o campo da Psiquiatria francesa durante e após o final da Segunda Guerra Mundial, e seus conceitos são ainda hoje determinantes nos tratamentos das patologias graves psiquiátricas. Alguns vislumbraram nesse campo uma ideologia psicanalítica quando, na verdade, trata-se, ao contrário, de ampliar a Psicoterapia Institucional ao tratamento de patologias que Freud e seus alunos não haviam considerado. Além disso, a Psicoterapia Institucional se interessa pela relação com a política e, principalmente, com tudo o que diz respeito aos fenômenos de exclusão e de segregação dos quais geralmente são vítimas os doentes mentais.

Tosquelles dizia que a Psicoterapia Institucional caminha sobre duas pernas, uma psicanalítica e uma política, 
o que mostra a complexidade do problema, que nunca pode ser reduzido a uma única abordagem, porque requer várias: Psicopatologia Psicanalítica, Neurociências, Antropologia, Sociologia. Esse movimento, que transformou de modo notável a maior parte dos hospitais psiquiátricos infantis de que fomos os herdeiros, contribuiu fortemente para humanizar a Psiquiatria, e seus profissionais reconhecem a importância de sua ação nesse processo histórico, inclusive em matéria de autismo.

No entanto, o autismo se tornou um objeto de conhecimento muito sensível em nosso país. Ele cristaliza conflitos entre os profissionais psis (Tosquelles, 2006) que dedicaram uma parte de sua vida profissional à tentativa de compreendê-los e tratá-los, apoiando-se principalmente nos trabalhos psicopatológicos, tornados possíveis graças à Psicanálise revisitada e aos terapeutas comportamentalistas que também investiram muito em uma perspectiva essencialmente (re)educativa.

Alguns pais, cada vez mais informados sobre essas problemáticas, tomaram partido a favor de um campo, o segundo, de modo maciço e, às vezes, passional. Certas associações de pais, as mais visíveis em termos midiáticos, tornaram-se progressivamente proeminentes em uma guerra contra a Psicanálise, misturando no mesmo ódio os psiquiatras de diversas orientações, a partir de então acusados de serem submarinos da Psicanálise. 
O ponto culminante desse conflito deletério ocorreu durante a preparação e a publicação das recomendações da HAS (Haute Autorité de Santê $)^{1}$ em 12 de março de 2013, data de memória sinistra na construção de uma cultura da complexidade. Depois disso, o plano proposto para tratamento do autismo apenas reforçou essas evidências truncadas que, infelizmente, se aplicam a muitos casos como tendo força de lei. Assim, a Psicanálise e a Psicoterapia Institucional foram condenadas ao desprezo e a técnica do packing ${ }^{2}$, reservada a alguns casos graves de automutilação, foi simplesmente proibida fora do enquadre da pesquisa realizada por mim no Centro Hospitalar Universitário de Lille (Delion, 2013). Nessas condições, os pais tornaram-se reféns das forças que os superam amplamente, incitando-os a abandonar o âmbito reservado aos problemas médicos, e ao acessar fóruns de internet que veiculam tanto as melhores quanto as piores informações, leva-os a ter uma posição contra os profissionais da Psiquiatria Infantil em numerosas ocorrências.

Para mim não se trata de minimizar a responsabilidade de alguns psiquiatras de formação psicanalítica no surgimento desse fenômeno atual. Há algum tempo venho denunciando os discursos "psicanaliticoides", mistura de certezas e desdém com os interlocutores, que trabalham com crianças autistas sem a participação dos pais, sem nada dar-lhes para pensar, e que negam a ausência evidente de resultados na evolução das crianças.

Os pais que tiveram de sofrer tais maus-tratos por parte desses personagens, pouco recomendáveis, não encontraram o meio de falar de seu ressentimento, ou mesmo de criticar seu comportamento insuportável, incompatível com o sofrimento de educar tal criança. Mas condenar a Psicanálise pela falta de empatia e de competência de alguns de seus pretensos membros não é uma atitude razoável. Será que eu deveria pedir a supressão da cirurgia sob o pretexto de que o cirurgião não conseguiu realizar a operação que deveria melhorar meu estado de saúde? Não, é claro! Mas a Psiquiatria Infantil não tem o status protegido da cirurgia, principalmente em sua relação com a ciência. A cirurgia é uma especialidade que repousa, doravante, em grande parte sobre a Medicina baseada em provas.

A Psiquiatria Infantil ainda não atingiu esse ponto, e o autismo, em seu seio, ainda menos, apesar do que gostariam de difundir alguns cientistas do autismo que, reputados por suas descobertas em termos de Genética, de Neurociências, de Psicologia do desenvolvimento, pensam poder dizer a verdade em todos os aspectos do autismo, 
inclusive sobre os aspectos dos quais nada sabem. Um especialista do câncer digestivo poderia impor sua opinião a um neurocirurgião sobre a via de abordagem para a ablação das metástases cerebrais?

Foi o que ocorreu com as recomendações sobre o autismo com relação à decisão equivocada de não se reconhecer a utilidade da Psicanálise e da Psicoterapia Institucional em seu tratamento. $\mathrm{O}$ packing, notável tratamento "ecológico" das automutilações (Delion, 2007), foi vítima das mesmas errâncias pseudocientíficas, já que não há nenhum artigo científico que demonstre os inconvenientes dessa técnica. No entanto, ele foi proibido com base na crença em argumentos ideológicos. Aqui o lobby substituiu a iniciativa científica, e as consequências desse abuso de autoridade estão longe de se encerrar, principalmente, para as crianças em questão e seus pais.

Regularmente recebo pais que vêm me pedir um packing para seu filho automutilador, apesar da proibição da HAS. Nesse contexto, fui violentamente atacado por muito pais em fóruns especializados em questões do autismo, ao me chamarem de bárbaro e outros nomes injuriosos. Insisto no fato de que todos os pais que assim se expressavam não me conheciam, tornando-se o instrumento de calúnias cuidadosamente difundidas pelos organizadores do lobby, aos quais atribuo um grande talento para a manipulação. Por outro lado, os pais com quem trabalho há quarenta anos tentando acompanhar seus filhos autistas escreveram testemunhos, com seus pontos de vista, autorizados, com muito rigor e comprometimento. Foram eles que me permitiram continuar apesar desse tsunami de ódio incompreensível. A partir da experiência com eles descreverei neste artigo o lugar dos pais das crianças autistas.

Quando recebo pais de um bebê com risco autístico ou de uma criança autista cujo diagnóstico foi estabelecido, proponho habitualmente a imagem de um tripé sobre o qual repousará o tratamento que iremos elaborar juntos a partir da seguinte equação: educativo sempre, pedagógico, se possível, e terapêutico, se necessário.

O primeiro elemento - educativo sempre - impõe-se a nós. Os pais são de fato os educadores de seus filhos. Ocorre que em certas circunstâncias a criança apresenta uma particularidade que os obriga a desenvolver sua função educativa de modo um pouco diferente. Por exemplo, uma criança surda. Seus pais, depois do diagnóstico, vão receber a proposta de uma ajuda em termos de linguagem de sinais, para que a criança, através dessa linguagem específica, desenvolva os meios de se comunicar com eles. Eles não são despossuídos de sua 
função educativa, mas melhoram as competências com a ajuda de educadores especializados que lhes ensinam a linguagem de sinais.

Os pais de uma criança autista têm constantemente dificuldades porque essa patologia faz fracassar a própria intersubjetividade assim como os meios de se comunicar. Em muitos casos os pais atravessam um momento em que a dúvida os assalta e os conduz a se perguntarem se são bons pais. Alguns se deprimem, muitos se culpam por não serem bem-sucedidos. Quando vêm ao consultório, muitas vezes somos os primeiros depositários desses profundos sentimentos de desvalorização pessoal que podem ser percebidos como depressão ou desânimo.

Esse estado clínico dos pais, responsável, para alguns espíritos em busca de uma causalidade simples, pelo aparecimento do autismo, mostra que eles têm que ser ajudados no plano pessoal para encontrarem em si mesmos forças para se tornarem os educadores que devem ser. Nessas circunstâncias, é interessante buscar a ajuda de educadores especializados no autismo para encontrar nessas técnicas os meios de retomar o contato com seus filhos.

Costumo perguntar aos pais o que eles pensam poder trazer benefícios para seus filhos. É quando eles me falam dos métodos que conheceram pela mídia ou em sites especializados. Quaisquer que sejam esses métodos, se os pais os consideram oportunos, são os que convêm à criança até outras informações. Assim, vejo pais utilizarem métodos TEACCH, ABA ou outros sem que isso seja muito formalizado. Em contrapartida, quando os pais pedem minha opinião sobre qual método educativo utilizar, discutimos amplamente sobre uma educação que corresponda não somente à sua filosofia, mas também aos recursos disponíveis no perímetro de sua vida cotidiana.

O segundo determinante - pedagogia, se possível - é o da escola. Contrariamente ao que foi dito e feito durante muito tempo, parece-me importante que uma criança autista receba um ensino pedagógico, sob condição de saber adaptá-lo às suas características pessoais e de levar em conta os recursos de seu ambiente. Desse modo, uma criança de 3 anos terá a experiência da entrada na escola. Se as coisas se passam sem outras dificuldades, teria sido uma pena privar-se disso. Por outro lado, os pedagogos pedem constantemente aos pais ajustes que lhes permitam melhor receber a criança: auxiliar de vida escolar para a criança, auxiliar de vida escolar coletiva, integração em classes 
especializadas para o acolhimento de crianças autistas.

Em alguns casos, o nível intelectual da criança não lhe permite permanecer, de modo profícuo, em uma classe comum e ela deve ser encaminhada para um estabelecimento médico-social. Finalmente, pode ocorrer que a criança apresente um estado clínico de tal angústia que a única solução seja encaminhá-la a um hospital-dia de seu setor de Psiquiatria Infantil, onde ela terá, junto com cuidados especializados, um professor colocado à disposição pela educação nacional para exercer a função pedagógica articulada com a equipe de tratamento.

O terceiro aspecto - terapêutico, se necessário - só será considerado quando os dois primeiros aspectos não bastarem para permitir um atendimento da criança autista na família e na escola. Este será o caso na medida em que os pais, nas consultas regulares conosco, falam da persistência ou do retorno de transtornos específicos do autismo, as angústias arcaicas. Tal criança pode se integrar bem na escola, mas sua alimentação é problemática em casa e toda refeição é um momento de angústias desestruturantes que não apenas a deixam mal, mas perturbam igualmente o conjunto familiar.

Outra criança parece ter benefícios em casa com acompanhamento educativo, mas manifesta sinais de angústias problemáticas na escola sob forma de estereótipos incoercíveis e 
até mesmo de automutilações. Uma outra pode ter atitudes de retraimento cada vez mais frequentes, angústias subjacentes ativas que a afastam da possibilidade de estar com os outros, tanto na família quanto na escola. Em casos como esses, proponho aos pais horários de atendimento no hospital-dia, em meio período se a inclusão escolar pode continuar sem muitas dificuldades, ou em período integral (durante a semana) se a criança manifestar grandes angústias que requerem um tratamento terapêutico contínuo.

No tratamento terapêutico, um primeiro tempo é dedicado à observação da criança em diferentes situações, de modo a compreender os fatores que favorecem a emergência de angústias e, ao contrário, os que as acalmam. Desse modo, estabelecemos uma espécie de "mapa do tesouro" da criança que nos possibilita uma melhor percepção das circunstâncias em que essas angústias vêm testemunhar o fracasso de suas defesas habituais e o recurso obrigatório à sua manifestação, muitas vezes, aguda. Elaboramos então um plano de tratamento, uma espécie de "termo terapêutico sob medida" que é resultado de todas essas observações realizadas em meio hospitalar e cruzadas com as dos pais. Constatamos que as crianças podem se apoiar nos cuidadores para ultrapassarem as etapas que lhes permitem superar esses momentos difíceis e reencontrar as competências anteriormente adquiridas e, assim, retomar seu desenvolvimento.

Para isso, a equipe de tratamento deve garantir uma primeira função que qualifico como função fórica, (Delion, 2013) que consiste em receber as crianças e acompanhá-las física e psiquicamente durante todo o tempo necessário até que elas mesmas possam fazê-lo.

Nessas experiências partilhadas com as crianças, a equipe recebe os elementos observados nas crianças, conscientes e inconscientes, e tornam-se portadores desses elementos. Assim, eles garantem uma função semafórica (sema/phorein: carregar os sinais de sofrimento da criança). $O$ fato de participarem de reuniões com todas as pessoas em contato com uma criança, a constelação transferencial, não significa que eles possam dar sentido a essas experiências vividas juntos. O sentido resulta da partilha dos testemunhos da equipe, entre eles mesmos, e com os pais. É o modo de garantir uma função metafórica. 
Para mim, o que é muito importante é prolongar o trabalho com os pais de modo a fazer que eles participem desse trabalho metafórico, pois são eles que conhecem melhor a história de seus filhos, e muitas vezes o sentido surge a partir de um vínculo estabelecido entre um comportamento problemático e um evento ocorrido anteriormente, mas despercebido.

Yohann é uma criança autista de 5 anos que se automutila gravemente, o que conduz a equipe de tratamento a decidir por um packing com ele. Os pais estando de acordo, os envelopamentos começam com três sessões por semana. No início, ele tenta bater a cabeça durante os envelopamentos. Progressivamente, ele abandona esse comportamento e grita regularmente suas angústias arcaicas aos cuidadores do packing.

E depois, um dia, ele começa a produzir lalações idênticas às de um bebê: "lalala". E, durante uma sessão memorável, ele diz claramente "ala". A reunião de constelação faz associações em torno dessa produção sonora, e uma enfermeira se lembra que na época de sua entrada no hospital ele gostava de ouvir a canção "elle a ce petit je ne sais quo?' [ela tem essa coisinha que não sei o que é]. Mas se "elle a" parece com "ala", as pessoas presentes durante esse packing não se convencem com essa explicação.

$\mathrm{Na}$ consulta semanal com os pais, eu lhes falo sobre nossa descoberta, e antes mesmo que eu acabe a frase, a mãe de Yohan começa a chorar. Mais calma, ela diz que "à la (ala) Claire Fontaine era a única canção que o fazia dormir". A função metafórica só pôde advir por meio da presença dos pais que deram sentido a algo que nos parecia insensato. Essa é a condição da aliança de trabalho com os pais em torno de seu filho. Os encontros com eles se referem principalmente à vida cotidiana em casa e no hospital-dia. Os pais se sentem compreendidos quando nos vemos, enquanto equipe de tratamento, diante de aspectos difíceis de seu filho. Às vezes não somos bem-sucedidos ali onde eles têm melhor resultado e inversamente.

A possibilidade de um trabalho com os pais torna possível a evolução do tratamento. Se os pais não conseguem dizer o que é difícil, não conseguimos ter com eles uma harmonia suficiente para poder partilhar os progressos, bem como as dificuldades. A função psicoterapêutica está contida nessa partilha de boa qualidade em torno da criança. E, do mesmo modo, as relações com os outros profissionais já mencionados são essenciais nesse trabalho de equipe: com os educadores e com os pedagogos. $\mathrm{O}$ que Duprée (1948), sociólogo belga, chamou de "relações complementares" encontra aqui todo seu lugar. $\mathrm{Na}$ medida em que cada um participa com suas próprias competências do trabalho geral a serviço da criança, esta pode ser beneficiada por cada uma. De modo contrário, quando cada um dos parceiros pensa e faz saber que ele é o mestre do tratamento e que, 
consequentemente, os outros são seus subordinados, a criança se torna o objeto do narcisismo de um dos membros da pseudoequipe, e a função continente e protetora da evolução da criança se torna a afirmação de uma única pessoa. A criança sente essa rachadura, os pais ficam pesarosos, e o tratamento termina em clivagens destrutivas para todos, favorecendo a eclosão de discursos ideológicos defensivos e sem futuro para a criança em questão.

Minha longa experiência mostra que o ensino da Psicoterapia Institucional é particularmente interessante para se pensar o tratamento da criança autista com seus pais e com os profissionais necessários, do modo mais próximo à vida cotidiana, e que a função psicoterápica se exerce então "como algo a mais".

Com efeito, os autismos infantis e suas variedades clínicas são patologias que colocam em jogo a intersubjetividade em todos os níveis de aceitação. Os pais serão os primeiros a se sentir desqualificados e virão procurar profissionais para sair desse estado de impossibilidade de se comunicar com seu filho.

Os profissionais podem considerar, de modo simplificador, que os pais devem ser ajudados a remediar as falhas de seu filho por abordagens reeducadoras e pedagógicas. No caso de resultados na entrevista, fica claro que essa iniciativa é suficiente. Mas em certo número de situações, isso não será suficiente, e a criança deverá ser ajudada pela terapêutica. Nesse caso, os funcionamentos herdados da Psicoterapia Institucional são os mais pertinentes, pois podem levar a equipe de tratamento em Psiquiatria Infantil a organizar dispositivos que considerem as especificidades de cada criança, e, assim, auxiliar a transformação dos elementos impensáveis em elementos assimiláveis por sua própria psique, e a retomada do desenvolvimento.

Nessa epopeia, é evidente que a cultura psicanalítica, sob condição de ser repensada à luz do autismo e da psicose infantil, apoiando-se em instituições, tais como a constelação transferencial, tem um lugar considerável no tratamento das crianças em sofrimento. Mas, ao lado dessas experiências numerosas, também é preciso integrar os aportes da Genética, das Neurociências e das outras Ciências Sociais conexas em um olhar complementar (Devereux) da Psiquiatria Infantil contemporânea. Tais perspectivas são essenciais para a melhoria dos tratamentos das crianças autistas.

Sem dúvida a solução só pode surgir a partir da consideração da complexidade na qual a simplificação não pode se acomodar. Enfim, a Psiquiatria Infantil deve conservar sua face humana para que as crianças 
possam ser beneficiadas por um tratamento que as "conduza" para as margens da alteridade, e para que os pais sejam considerados como aliados dos profissionais, sempre e em toda parte.

\section{AUTISM AND PARENTING}

\section{Abstract}

Autistic disorders are complex and require a specific treatment for each child. For the organization that presides over the care, Institutional Psychotherapy movement is important because of its vast experience with severe psychopathology, such as autism and psychosis. In the treatments proposed to the child, the place of parents is crucial in terms of guidance and essential to reassign sense. However, for various reasons, some parents may develop negative feelings in the presence of professionals that should be considered.

Index terms: childhood autism; parents; institutional psychotherapy; transfer; child psychiatry.

\section{REsumen}

\section{EL AUTISMO Y LA PARENTALIDAD}

Las patologías del autismo son complejas y se neces sitan de una atención especifica para cada niño. En la organización que ofrece atención, es importante el movimiento de la Psicoterapía Institucional debido a su larga experiencia con las psicopatologías graves, tales como el autismo y las psicosis. En los tratamientos propuestos al niño, el lugar de los padres resulta crucial en términos de orientación y es indispensable por reasignarles sentido. Sin embargo, por muchas razones, algunos padres pueden desarrollar, en los profesionales, sentimientos negativos que deben considerarse.

Palabras clave: autismo infantil; padres; psicoterapia institucional; traslado; psiquiatría infantil.

\section{REFERÊNCIAS}

Delion, P. (2007). La pratique du packing avec les enfants autistes et psychotiques en pédopsychiatrie. Toulouse: Erès.
Delion, P. (2009). Séminaire sur l'autisme et la psychose infantile. Toulouse: Erès. (Trabalho original publicado em 1997))

Delion, P. (2011). Accueillir et soigner la souffrance psychique de la personne. Paris: Dunod.

Delion, P. (2013). Ecouter, soigner la souffrance psychique de l'enfant. Paris: Albin Michel.

Delion, P. (2013). Donald Winnicott, Michel Tournier et la fonction phorique. In P. Delion, L'enfant et son psychisme (pp. 191202). Paris: Dunod.

Dupréel, E. (1948). Traité de sociologie générale. Paris: PUF.

Hochmann, J. (1976). Pour soigner l'enfant psychotique. Toulouse: Privat.

Misès, R. (1980). La cure en institution, coll. La vie de l'enfant. Paris: ESF.

Oury, J. (1986). Le collectif. Paris: Scarabée.

Tosquelles, F. (2006). Education et psychothérapie institutionnelle. Nîmes: Champs Social.

\section{NOTAS}

1. N. do T.: Alta Autoridade de Saúde

2. O Packing é uma técnica de tratamento que consiste em envolver, transitoriamente, um paciente com panos frios e úmidos. Esta técnica, chamada de envelopamento, é usada tanto para crianças com autismo infantil como para adultos psicóticos, durante o período de recuperação após um episódio de descompensação com abundância de sintomas psicóticos positivos. pierre.delion@wanadoo.fr

2, avenue Oscar Lambert 59037 - Lille Cedex - France.

Recebido em dezembro/2014. Aceito em março/2015. 